University of Wollongong

Research Online

Faculty of Engineering and Information

Faculty of Engineering and Information

Sciences - Papers: Part A

Sciences

$1-1-2006$

\title{
Explicit dynamic FEM analysis of multipass vertical-horizontal rolling
}

Hai-liang Yu

Northeastern University, hailiang@uow.edu.au

Xiang-hua Liu

Northeastern University, liuxh@uow.edu.au

Xian-ming Zhao

Northeastern University

Di Wu

Northeastern University

Y Kusaba

Sumitomo Metal Industries

Follow this and additional works at: https://ro.uow.edu.au/eispapers

Part of the Engineering Commons, and the Science and Technology Studies Commons

Research Online is the open access institutional repository for the University of Wollongong. For further information contact the UOW Library: research-pubs@uow.edu.au 


\title{
Explicit dynamic FEM analysis of multipass vertical-horizontal rolling
}

\begin{abstract}
Three passes of plate rolling during vertical-horizontal rolling process are simulated with explicit dynamic finite element method and updating geometric method. The equivalent strain and stress fields, and shape change at the head and tail of slab during rolling are obtained. The calculated result of the shape at the head and tail of slab is in good agreement with the measured one. The explicit dynamic finite element method and updating geometric method can be used effectively to analyze the multipass verticalhorizontal (V-H) rolling process. (c) 2006 Central Iron and Steel Research Institute.

\section{Keywords}

vertical, dynamic, horizontal, fem, rolling, explicit, analysis, multipass

Disciplines

Engineering | Science and Technology Studies

\section{Publication Details}

Yu, H., Liu, X., Zhao, X., Wu, D. \& Kusaba, Y. (2006). Explicit dynamic FEM analysis of multipass verticalhorizontal rolling. Journal of Iron and Steel Research International, 13 (3), 26-30.
\end{abstract}




\title{
Explicit Dynamic FEM Analysis of Multipass Vertical-Horizontal Rolling
}

\author{
YU Hai-liang ${ }^{1}, \quad$ LIU Xiang-hua ${ }^{1}, \quad$ ZHAO Xian-ming ${ }^{1}, \quad$ WU Di $^{1}, \quad$ Y. Kusaba ${ }^{2}$ \\ (1. State Key Laboratory of Rolling and Automation, Northeastern University, Shenyang 110004, Liaoning, China; \\ 2. Sumitomo Metal Industries Ltd, Fuso-Cho 660, Amagasaki, Japan)
}

\begin{abstract}
Three passes of plate rolling during vertical-horizontal rolling process are simulated with explicit dynamic finite element method and updating geometric method. The equivalent strain and stress fields, and shape change at the head and tail of slab during rolling are obtained. The calculated result of the shape at the head and tail of slab is in good agreement with the measured one. The explicit dynamic finite element method and updating geometric method can be used effectively to analyze the multipass vertical-horizontal (V-H) rolling process.

Key words: V-H rolling; multipass; equivalent stress; strain; slab shape
\end{abstract}

Vertical rolling (also referred to edge rolling or slab edging) with a plain-barreled roll is one width reduction method in the roughening strains of a hot strip mill, which deforms the slabs in the width direction and gives rise to the 'dog-bone' slab shape formation at the same time. The horizontal rolling stand is subsequently adopted to flatten the ' $\mathrm{dog}$ bone' shape and to reduce the thickness of the slab. The combination of the above two processes is often called vertical-horizontal ( $\mathrm{V}-\mathrm{H})$ rolling, which is still an important method, world-wide, for heavy width reduction in the roughing stands of a hot strip mill. The deformation behavior of the material has mainly been investigated experimentally ${ }^{[1-3]}$. However, using physical simulation is hard to do quantitative analysis and get mathematical rules, and the more difficult thing is to analyze the regularity of stress and strain. At the same time, finite element method (FEM) was widely applied during solving vertical-horizontal rolling problems ${ }^{[4-12]}$. For example, the rigid-plastic formulation and some simplified assumptions were taken into account by $\mathrm{K}$ Mori and $\mathrm{K}$ Osakada ${ }^{[4]}$, an elastic-plastic finite element formulation was used by $\mathrm{H} \mathrm{J}$ Huisman and $\mathrm{J}$ Huetink $^{[5]}$ to investigate the effect of roll diameter on the deformation of an edge-rolled slab, and incremental visco-plastic model by $\mathrm{C}$ David et $\mathrm{al}^{[6]}$ as- sumed a dog-bone shape as the function of friction. Meantime, the whole $\mathrm{V}-\mathrm{H}$ rolling process has been also studied by $\mathrm{H} \mathrm{Nikaido}^{[7]}$, XIONG Shang$\mathrm{wu}^{[8-10]}$, ZHAO Xian-ming ${ }^{[11]}$ and W K Chung ${ }^{[12]}$ et $\mathrm{al}$, in which the simulation was only made in one pass. Recently some researchers ${ }^{[11-16]}$ have employed explicit dynamic FEM, which doesn't require iterative solution, to analyze plate rolling problems. For analysis of hot rolling process, it is assumed that the temperature is invariable. Some research$\mathrm{ers}^{[13.14]}$ have analyzed hot rolling using explicit dynamic FEM successfully.

In present study, the explicit dynamic finite element software LS-DYNA and updating geometric method were used to simulate three passes of $\mathrm{V}-\mathrm{H}$ rolling a plain carbon steel, and the equivalent stress and strain fields, and the shape change at the head and tail were analyzed.

\section{Basic Theory}

\subsection{Explicit dynamic FEM}

The fundamental equation of explicit dynamic FEM is

$$
M \ddot{u}+C \dot{u}+F=R
$$

where $\ddot{u}$ is nodes' acceleration; $\dot{u}$ is nodes' velocity; $M$ is mass matrix; $C$ is damping matrix; $F$ is vector 
of inner force; and $R$ is vector of outer loads.

Compared with static analysis, the mass matrix and damping matrix are introduced into equilibrium equation of dynamic analysis because of the existence of inertia force and damping force. The final solution equations are ordinary differential equation groups instead of algebraic ones. Generally, the Eqn. (1) can be obtained by integrating central finite difference method, which belongs to immediate integration method. In this method, the discrete velocity and acceleration at time $t_{\mathrm{n}}$ can be expressed as

$$
\begin{aligned}
& \dot{u}_{n}=\frac{1}{2 \Delta t}\left(u_{n+1}-u_{n-1}\right) \\
& \ddot{u}_{n}=\frac{1}{\Delta t^{2}}\left(u_{n+1}-2 u_{n}+u_{n-1}\right)
\end{aligned}
$$

Substituting the Eqn. (2) and Eqn. (3) into Eqn. (1), the discrete time recursion relation is obtained.

$$
\begin{aligned}
u_{n+1}= & {\left[M+\frac{\Delta t}{2} C\right]^{-1}\left[\Delta t^{2}\left(R_{n}-F_{n}\right)+\right.} \\
& \left.2 M u_{n}-\left(M-\frac{\Delta t}{2} C\right) u_{n-1}\right]
\end{aligned}
$$

The central difference method is stable under certain condition that the time step $\Delta t$ must be lower than one critical value $\Delta t_{\min }$, which is determined by the feature of the equation. Otherwise, the algorithm will be unstable. Generally, according to the Courant-Friedrichs-levy stability criterion, the value is

$$
\Delta t_{\min }=\frac{2}{w_{\max }}=\frac{l}{c}
$$

where $w_{\max }$ is maximum natural frequency of system; $l$ is element's characteristic length, and is equal to the shortest distance of any two nodes in the element; $c$ is sound velocity in the material. For 3-D element, the sound velocity in the material is

$$
c=\sqrt{\frac{(1-v) E}{(1+v)(1-2 v) \rho}}
$$

where $E$ is Young's modulus; $v$ is Poisson's ratio; $\rho$ is material's density.

\subsection{Updating geometric method}

The updating geometric method is that displacement from the previous analysis is added to update the current geometry of the finite element model for the deformed configuration, subsequently creating a revised geometry at the deformed configuration. This method works on all nodes or on a selected set of nodes. If this method is issued repeatedly, it creates a revised geometry of the finite element model in a cumulative type, i. e. , it adds displacement results on the previously generated deformed geometry, and the solid model geometry is not updated by this method.

\section{Parameters of Finite Element Simulation}

In this simulation, the process parameters for analysis are listed in Table 1 and Table 2. Bilinear isotropic hardening material model is adopted for the slab, and the main chemical composition of the slab is: C $0.18, \mathrm{Si} 0.32$, and $\mathrm{Mn} \mathrm{0.82}$. The yield stress at high temperature is related to true strain $\varepsilon$, true strain velocity $\dot{\varepsilon}$, deformation temperature $T$. During this simulation, the yield stresses were calculated by the Eqn. (7).

$$
\sigma=A \varepsilon^{B} \varepsilon^{* C T+D} e^{F T}
$$

where $A, B, C, D, F$ are constant; and $e$ is napierian base.

Table 1 Process parameters

\begin{tabular}{lc}
\hline Vertical roller diameter $/ \mathrm{mm}$ & 980 \\
Horizontal roller diameter $/ \mathrm{mm}$ & 1150 \\
Slab dimension $/ \mathrm{mm}^{3}$ & $1500 \times 1200 \times 250$ \\
\hline
\end{tabular}

Table 2 Rolling and calculation conditions

\begin{tabular}{lccc}
\hline & $\begin{array}{c}\text { First } \\
\text { pass }\end{array}$ & $\begin{array}{c}\text { Second } \\
\text { pass }\end{array}$ & $\begin{array}{c}\text { Third } \\
\text { pass }\end{array}$ \\
\hline Vertical roller width/mm & 1150 & 1100 & 1050 \\
Horizontal roller height/mm & 240 & 240 & 240 \\
Rolling temperature/ $\mathrm{C}$ & 880 & 862 & 840 \\
Rolling velocity/(m $\left.\cdot \mathrm{s}^{-1}\right)$ & 4 & 4 & 4 \\
Friction coefficient & 0.35 & 0.35 & 0.35 \\
\hline
\end{tabular}

\section{Model}

Owing to the symmetry of slab and rollers, $1 / 4$ of slab and rollers were considered in the geometric model. According to the given parameters above, the rolling model of the first pass was built. The rollers were assumed to be rigid because rolling temperature was high, and deformation was so little that it could be neglected. At the same time, only the elements near the slab edge were refined where the deformation centralized. The whole model used SOLID164 which is a kind of element, and was dispersed with eight nodes and hexahedral elements. The nodes on the bottom face of slab were constrained whose displacements along $Y$ direction were zero, so were the nodes on the center face of slab whose displacements along $Z$ direction were zero. There were 28654 nodes and 24268 elements in the 
whole model, in which there were 27573 nodes and 24000 elements belonging to the slab. The finite element model of the first pass is shown in Fig. 1. In the meantime, the rolling models for the second pass and the third pass were obtained by updating geometry, modifying material attribute, boundary condition, and loads, which made the simulation of rolling process continuous and true, and saved the resource of computer. All the slab models of three passes before simulation and computation were shown in Fig. 2.

\section{Results and Discussion}

\section{1 Slab's equivalent strain}

The equivalent strain distribution of same element under six rolling conditions is shown in Fig. 3. It is clear that the equivalent strain centered in a litthe zone of slab near the slab corner and close to vertical roller or horizontal roller, and didn' $t$ go deep into slab as slab formed the "dog-shape" when roll-

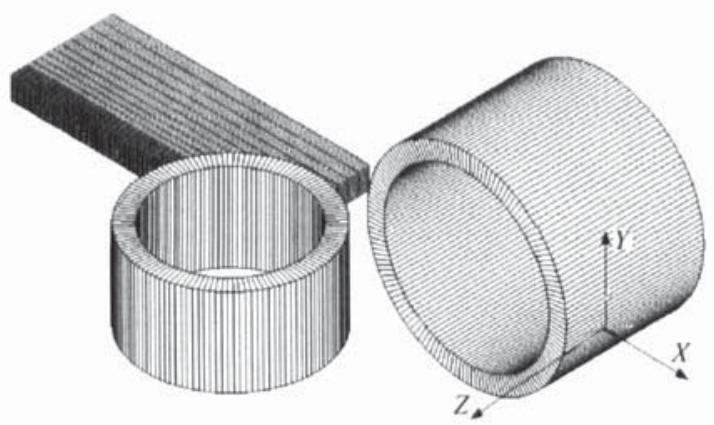

Fig. 1 Geometric model and meshing
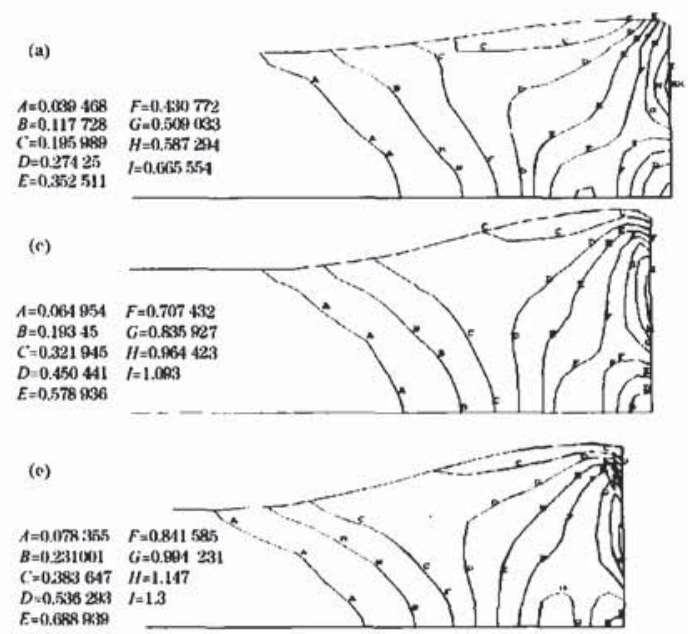

ing. For horizontal rolling, the two strain concentration zones were thinner.

\section{2 Stress}

The residual stress contour distribution at same profile of slab after six different rolling conditions is shown in Fig. 4. It can be seen that stress gradient is high near the high strain zones compared with Fig. 3. And with the rolling process, the stress distribution becomes more complex.

\section{3 Slab edging}

Nodes at one section of slab near slab corner whose dislocation change tendency along $Y, Z$ directions during three passes of $\mathrm{V}-\mathrm{H}$ rolling are shown in Fig. 5. From the figure, the position of nodes at any time during rolling process can be known, which
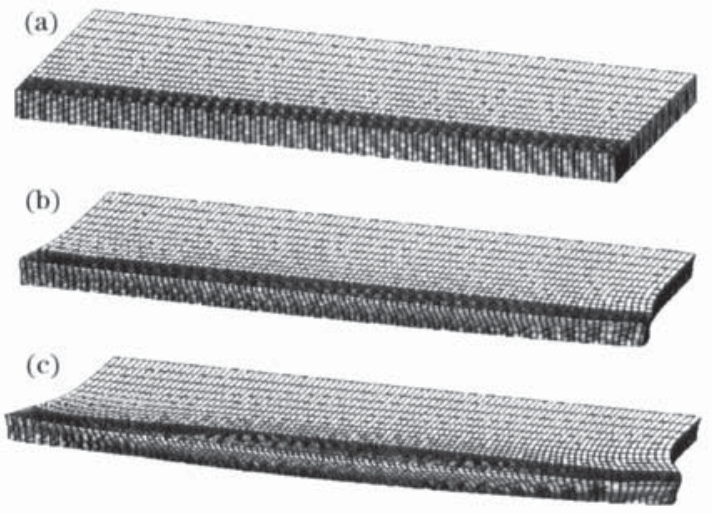

Fig. 2 Geometric model and meshing of slab for first pass (a), second pass (b) and third pass (c)
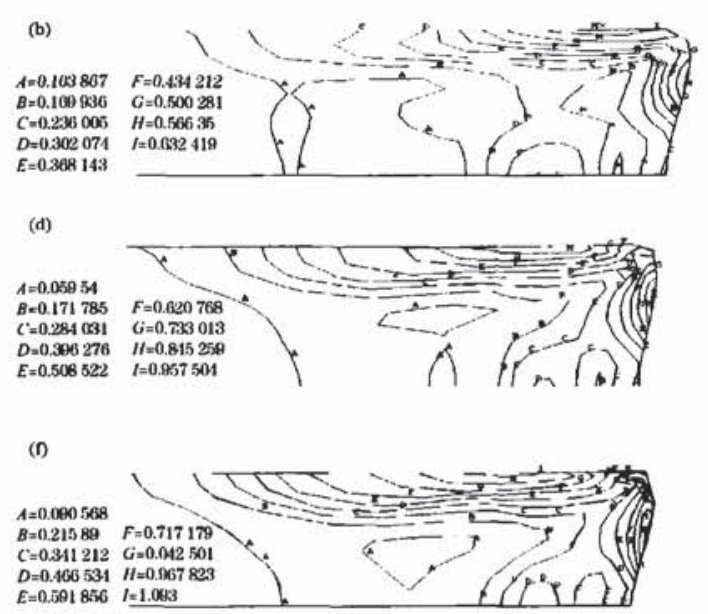

(a) After vertical roller in first pass,

(b) After horizontal roller in first pass;

(c) After vertical roller in second pass;

(d) After horizontal roller in second pass;

(e) After vertical roller in third pass;

(f) After horizontal roller in third pass

Fig. 3 Equivalent strain contour distribution of slab 


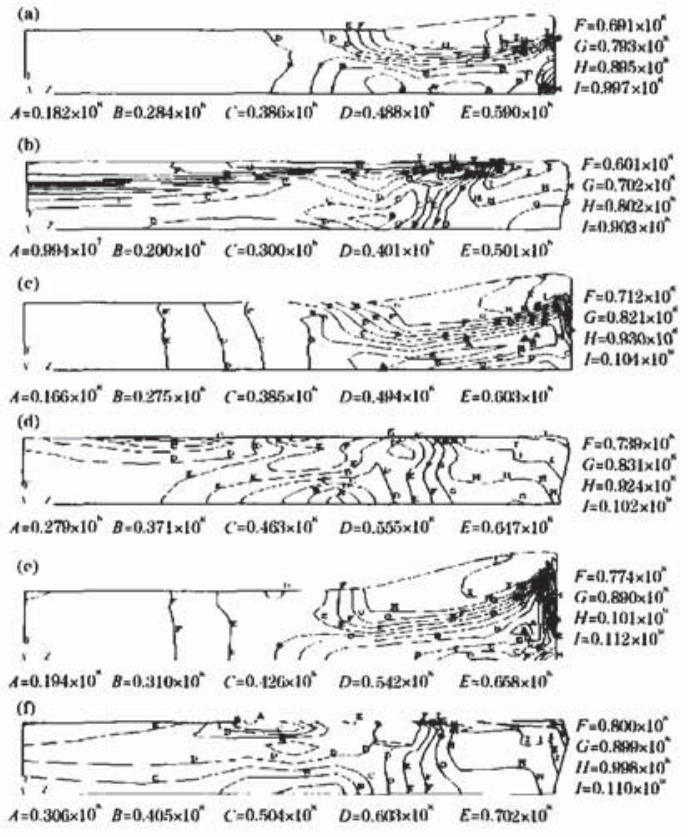

(a) After vertical roller in first pass; $\quad$ (b) After horizontal roller in first pass; $\quad$ (c) After vertical roller in second pass; (d) After horizontal roller in second pass; $\quad$ (e) After vertical roller in third pass; (f) After horizontal roller in third pass

Fig. 4 Equivalent stress contour distribution of slab

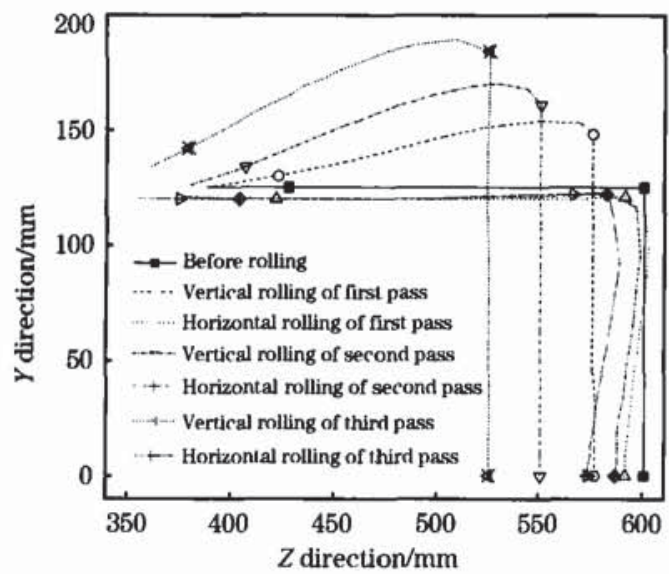

Fig. 5 Displacement of nodes at slab corner during rolling process

may be helpful for tracing the original crack. And it could be found that after multipass $\mathrm{V}-\mathrm{H}$ rolling, the slab corner metal moves to the slab top surface, which may be the reason that slab surface defects come from slab side surface.

\section{4 Shape change at slab head and tail}

Fig. 6 shows that the shape at the head and tail of slab changes at a 'fish-shape' during multipass $\mathrm{V}-\mathrm{H}$ rolling process. It could also be found that the

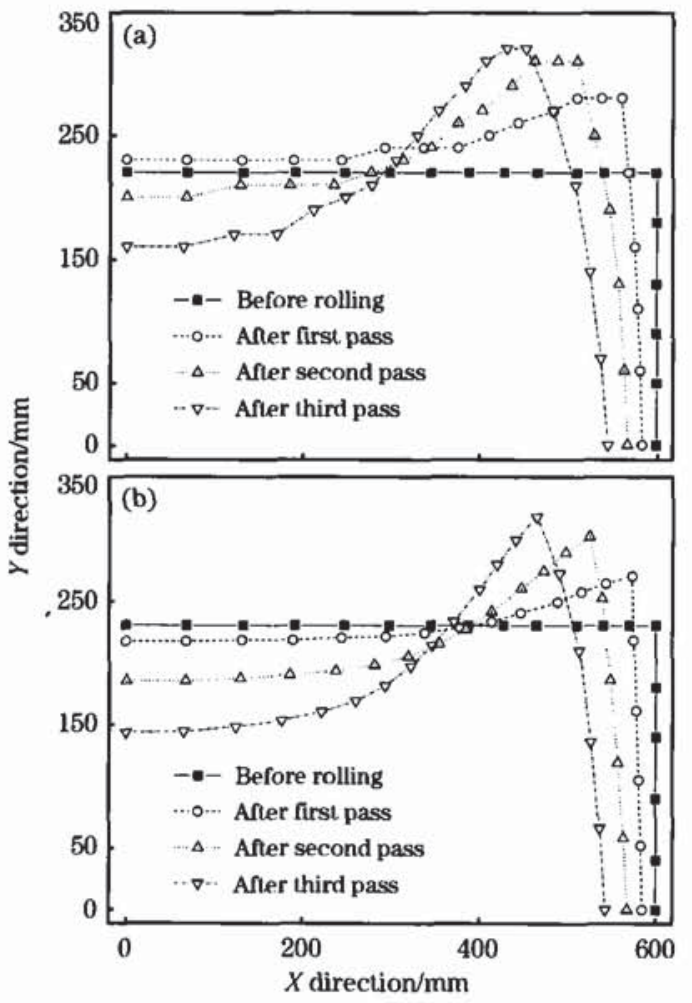

Fig. 6 Shape change of slab head (a) and slab tail (b)

'fish-shape' is harder and harder as the rolling pass increasing, and the non-uniform zone at slab tail is bigger than that at the slab head.

In order to make the explicit dynamic FEM and updating geometric method well simulate the multipass $\mathrm{V}-\mathrm{H}$ rolling process, an experiment of multipass $\mathrm{V}-\mathrm{H}$ rolling lead at room temperature is performed because the lead has characteristics similar to steel at room temperature. From Fig. 7, it can be seen that the calculated values are in good agreement with the actually measured ones.

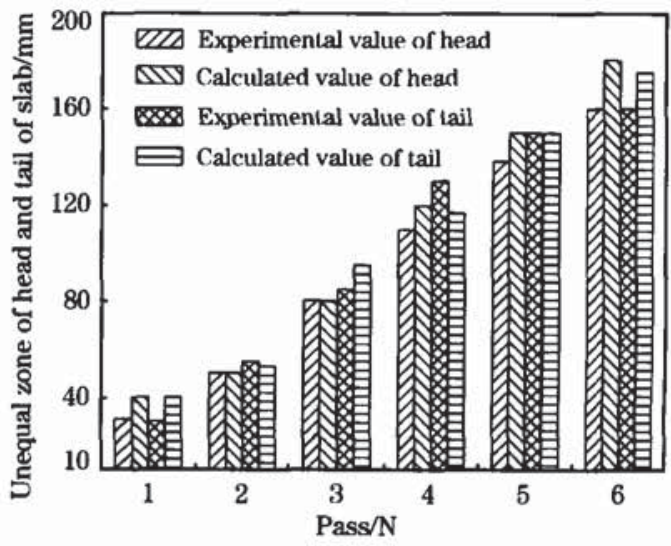

Fig. 7 Unequal zone of head and tail of slab 


\section{Conclusions}

(1) The V-H rolling model for the first pass was built, and the whole three passes were simulated with explicit dynamic FEM and updating geometric method, which made the whole rolling process continuous.

(2) During V-H rolling process, there are strain centralized zones near the slab corner, where the residual stress is centralized too.

(3) The calculated shape changes at the head and tail of slab are in good agreement with the measured ones. The results show that the multipass $\mathrm{V}-\mathrm{H}$ rolling process could be analyzed by means of explicit dynamics FEM and updating geometric method.

\section{References:}

[1] Okado M, Arizumi T, Noma Y, et al. Width Behaviour of Head and Tail of Slabs at Edging Rolling in Hot Strip Mills [J]. J Iron and Steel Inst Jpn, 1981, 67(15): 2516-2525.

[2] Ginzburg V B. Steel Rolling Technology: Theory and Practice [M]. New York: Marcel Dekker, 1989.

[3] XIONG Shang-wu, ZHU Xiang-ling, LIU Xiang-hua, et al. Mathematical Model of Width Reduction Process of Roughing Trains of Hot Strip Mills [J]. Shanghai Metals, 1997, 19(1): 39-42.

[4] Mori K, Osakada K. Simulation of Three-Dimensional Rolling by the Rigid-Plastic Finite Element Method [A]. Pittman J F $T$, Wood R D, Alexander J M, et al eds. Proceedings of the International Conference on Numerical Methods in Industrial Forming Processes [C]. Swansea: Pineridge Press, 1982. 747-756.

[5] Huisman H J, Huetink J. A Combined Eulerian-Langrangian Three-Dimensional Finite-Element Analysis of Edge-Rolling [J]. J Mech Work Technol, 1985, 21(11): 333-353.

[6] David C, Bertrand C, Chenot J L, et al. A Transient 3D FEM Analysis of Hot Rolling of Thick Slabs [A]. Mattiasson K,
Samuelsson A, Wood R D, et al, eds. Proceedings of Numiform' 86 [C]. Rotterdam, Netherlands: Balkema A A, 1986. 219-224.

[7] Nikaido H, Naoi T, Shibata K, et al. Numerical Simulation of Width Spread of Dog-Bone Slab in Non-Steady Horizontal Rolling [J]. J Jpn Soc Technol Plasticity, 1984, 25(277): 129135.

[8] XIONG Shang-wu, LIU Xiang-hua, WANG Guo-dong, et al. A Three-Dimensional Finite Element Simulation of the VerticalHorizontal Rolling Process in the Width Reduction of Slab [J]. J Mater Process Technol, 2000, 101(1): 146-151.

[9] XIONG Shang-wu, ZHENG Gui-fang, LIU Xiang-hua, et al. Analysis of the Non-Steady State Vertical-Horizontal Rolling Process in Roughing Trains by the Three-Dimensional Finite Element Method [J]. J Mater Process Technol, 2002, 120(13): $53-61$.

[10] XIONG Shang-wu, Rodrigues J M C, Martins P A F. ThreeDimensional Modeling of the Vertical-Horizontal [J]. Finite Elements in Analysis and Design, 2003, 39, 1023-1037.

[11] ZHAO Xian-ming, WANG Guo-dong, PARK Hae-doo. Influence of Vertical Roll Shape on Bar Camber by FEM and Analytic Modeling [J]. Journal of Northeastern University (Natural Science), 2002, 23(12): 1174-1176 (in Chinese).

[12] Chung W K, Choi S K, Thomson P F. Three-Dimensional Simulation of the Edge Rolling Process by the Explicit FiniteElement Method [J]. J Mater Process Technol, 1993, 38(12): 85-102.

[13] Esa Ervasti, ULF Stahlberg. Behavior of Longitudinal Surface Cracks in the Hot Rolling of Steel Slabs [J]. J Mater Process Technol, 1999, 94(2): 141-150.

[14] Esa Ervasti, ULF Stahlberg. Transversal Cracks and Their Behavior in Hot Rolling of Steel Slabs [J]. J Mater Process Technol, 2000, 101(1): 312-321.

[15] Iguchi T, Owen D R J, LIU G Q. Analysis of Rolling Processes by Dynamic Explicit Elastic-Plastic Finite Element Method [A]. Kiuchi M, eds. Proceedings of 7th International Conference on Steel Rolling (STEEL. ROLLING'98) [C]. Chiba: Iron and Steel Institute of Japan, 1998. 266-271.

[16] LIU Li-zhong, LIU Xiang-hua, JIANG Zheng-yi. Strip Rolling Simulation by the Dynamic Explicit FEM [J]. Journal of Plasticity Engineering, 2001, 8(1): 51-54 (in Chinese). 